case of a random binary sequence in which the dependence of the fractal dimension on the width of the partition of the sequence on the rectangles is shown. Based on the presence of such dependence, a requirement is made to perform partitioning in the ranges used to solve specific problems. The results can be used to improve the simulation of fractal random sequences; mass service systems; simulation of traffic of telecommunication networks.

The result of the practical verification of the mathematical expectation of fractal dimension with different partitions testifies to the dependence of the fractal dimension on the scaling of the partition. This means that from the selected scale of the partition into rectangles, it is possible to get an arbitrary value of the dimension from 1 to 2 , which is quite significant when considering the limiting cases. In particular, with a fairly wide division, when a rectangle contains a large number of elements of a numerical sequence, the height of the rectangle covers almost the entire permitted range of the realization of random values; A sequence of almost equal to the height of rectangles is formed, which is an analogue of a two-dimensional strip, which almost does not change its width with increasing partition. According to the logical construction, the strip is a twodimensional object, and the exit from the band in practice is forbidden by physical real processes in which no unlimited signal growth is allowed.

fractal dimension, numerical sequence, probability distribution, random, ergodic, process

Одержано (Received) 15.05.2018

\title{
УДК 004.41:004.056
}

О.В. Коваленко, доц., канд. техн. наук

Центральноукраїнський національний технічний університет, м.Кропивницький, Украӥна, E-mail: Clashav@gmail.com

\section{Управління ризиками розробки програмного забезпечення за умови обмеженості коштів виділених на усунення помилок безпеки}

В даній роботі задача управління ризиками розробки ПЗ за умови обмеженості коштів (фінансових, технічних та ін.), виділених на усунення помилок безпеки, розглядається у вигляді напівмарківської моделі прийняття рішень для керованого процесу у безперервному часі 3 критерієм мінімуму витрат на усунення аномалій. Для вирішення задачі пропонується метод управління ризиками розробки ПЗ, який відрізняється від відомих використанням псевдобулевих методів бівалентного програмування з нелінійною цільовою функцією і лінійними обмеженнями для визначення оптимальної стратегії усунення експлуатаційних помилок. Як приклад розглянуті ситуації виникнення помилок безпеки ПЗ і визначена оптимальна стратегія управління для усунення вказаної аномальної ситуації. розробка програмного забезпечення, управління ризиками, псевдобулевий метод

А. В. Коваленко, доц., канд. техн. наук

Центральноукраинский наџиональный технический университет, г.Кропивниџкий, Украина

\section{Управление рисками разработки программного обеспечения при условии} ограниченности средств выделенных на устранение ошибок безопасности

В данной работе задача управления рисками разработки ПО при условии ограниченности средств (финансовых, технических и др.), выделенных на устранение ошибок безопасности, рассматривается в виде полумарковских моделей принятия решений для управляемого процесса в непрерывном времени с критерием минимума затрат на устранение аномалий. Для решения задачи предлагается метод управления рисками разработки ПО, который отличается от известных использованием псевдобулевих методов бивалентного программирования с нелинейной целевой функцией и линейными ограничениями для определения оптимальной стратегии устранения эксплуатационных ошибок. В качестве примера рассмотрены ситуации возникновения ошибок безопасности ПО и определена оптимальная стратегия управления для устранения указанной аномальной ситуации.

разработка программного обеспечения, управления рисками, псевдобулевый метод

(C) О.В. Коваленко, 2018 
Постановка проблеми. Загальні процеси глобалізації економічних, фінансових, соціальних та інформаційних відносин сприяли розвитку напрямку ризикменеджменту. Однак загальносвітові фінансові кризи показали недостатньо уважне ставлення до управління ризиками 3 боку більшості представників керівництва організацій, в тому числі і в Україні.

Управління ризиком розробки ПЗ полягає у завчасному виявленні пов'язаних 3 ризиком фінансових, технічних, психологічних та ін. небезпек, і вживанні заходів щодо зниження ризику шляхом цілеспрямованої зміни цих факторів 3 урахуванням ефективності вживаних заходів. Управління ризиком розробки ПЗ включає систему заходів, що здійснюються як до прояву негативної події, так і після його реалізації. Однак, як показали дослідження, превентивний аналіз і урахування більшості можливих експлуатаційних помилок дозволить знизити фінансові та ін. витрати в життєвому циклі розробки ПЗ [1-3].

Аналіз останніх досліджень і публікацій. Ряд авторів [1-6] під терміном «управління ризиком» розуміють розробку і обгрунтування оптимальних програм діяльності, покликаних ефективно реалізувати рішення в області забезпечення безпеки. При цьому головним елементом такої діяльності $є$ процес оптимального розподілу обмежених ресурсів 3 урахуванням характерних експлуатаційних, економічних $\mathrm{i}$ соціальних факторів.

Розглядувану задачу управління ризиками розробки ПЗ при визначених обмеженнях на заходи 3 тестування якості та безпеки сформулюємо у вигляді напівмарківської моделі прийняття рішень для керованого марківського процесу у безперервному часі і дисконтованими доходами (з коефіцієнтом $0<\alpha<1$ в нормальних умовах процесу створення ПЗ) або витратами (в умовах з відхиленнями від плану, пов'язаними з нехтуванням невиявлення вразливостей (помилок) безпеки). При цьому даний вид експлуатаційних ризиків ототожнюється 3 послідовно з'єднаними незалежними елементами, відновлюваними за кінцевий час.

Оптимальну нерандомізовану стаціонарну стратегію управління визначимо за допомогою псевдобулевих методів бівалентного програмування, знаходячи всі рішення системи обмежень. Ці рішення визначаються на основі алгоритму перетину рішень окремих нерівностей-обмежень, запропонованого в роботі [3, 7-9] для знаходження базисних рішень системи лінійних нерівностей з булевими змінними.

В таких умовах сформулюємо основну задачу. Нехай кожному стану $i \in S$, де $S=\{0,1,2, \ldots, N\}$ розглядуваної системи управління ризиками розробки ПЗ поставлена у відповідність кінцева множина $R_{i}$ рішень, елементи якої позначимо як $r=1,2, \ldots, r_{i}$. Якщо система знаходиться у стані $i \in S$ і приймається рішення $r=R_{i}$, то їі подальша поведінка визначається імовірнісним законом

$$
Y_{i j}^{r}(t)=P_{i j}^{(r)} F_{i j}^{(r)}(t), \quad j \in S,
$$

де $P_{i j}^{(r)}$-імовірність переходу системи із стану в стан $i ; F_{i j}^{(r)}(t)$-функція розподілу часу перебування системи в стані $i$ при прийнятті рішення $r$ і за умови, що наступний перехід відбудеться в стан $j$.

При цьому зробимо припущення, що виконані наступні умови:

- стан $i=0$ відповідає нормальному процесу розробки П3, а $i \neq 0$ - ситуація помилки безпеки;

- функції $F_{0 j}^{(r)}(t)$ і $F_{j 0}^{(r)}(t), j \in \widetilde{S}=S /\{0\}, \quad r \in R_{j}$, разом зі своїми першими похідними неперервні при $t>0$, за винятком кінцевого числа точок, і зростають відповідно до експоненціального закону розподілу; 
- за одиницю часу перебування в стані $i$ у випадку прийняття рішення $r$ витрачається у середньому $k_{i}^{(r)}$ коштів (при $i \neq 0$ число $k_{i}^{(r)}$ від’ємне і дорівнює витратам системи за одиницю часу перебування у стані $i$ за умови виходу із цього стану з урахуванням рішення $r$ );

- величини $\left|k_{i}^{(r)}\right|$ обмежені при всіх $i \in S, \quad r \in R_{i}$ і ймовірності $P_{i}^{(r)}$ задовольняють співвідношення:

$$
\sum_{j \in S} P_{i}^{(r)}=1, \quad i \in S, \quad r \in R_{i}, P_{i j}^{(r)} \geq 0, i, j \in S, \quad r \in R_{i} .
$$

Таким чином, у кожному стані $i \in S$ існує $r_{i}$ рішень із кінцевої множини $R_{i}$. Вибір деякого рішення $r$ із цієї множини $R_{i}$ в стані $i \in S$ означає завдання величин $Y_{i j}^{r}(t), P_{i j}^{(r)}, F_{i j}^{(r)}(t), k_{i}^{(r)}, j \in S$.

При $i=0, R_{0}=\{0\}$, імовірність $P_{0 j}^{(r)} \neq 0, j \in S \in$ ймовірністю переходу в стан $j$. Імовірність $P_{0 j}^{(r)} \neq 0, j \in S$ обчислюється на практиці як частка станів 3 помилками безпеки типу $j$ у загальній сукупності вразливостей безпеки різних типів на основі даних передісторій процесу розробки ПЗ. В цьому випадку $F_{0 j}^{(r)}(t)$ - функція розподілу часу тестової експлуатації ПЗ між виявленими помилками безпеки типу $j$.

При $i=1, \ldots, N$ для будь-якого $r \in R_{i}, P_{i 0}^{(r)}=1, \quad P_{i j}^{(r)}=0, j \neq 0$, функція $F_{i 0}^{(r)}(t)$ це функція розподілу часу усунення вразливостей безпеки з використанням рішення $r$ при помилці типу $j$.

За умови неперервності в часі досліджуваного процесу будемо користуватися переоцінкою експоненціального виду з нормою $\alpha$, тобто, якщо в деякий момент часу витрати становлять якусь одиничну величину, то через час $t$ ці затрати вже будуть $e^{-\alpha t}$ одиничних величин. Тоді, якщо $k_{i}$ - витрата за одиницю часу, то сумарна витрата за час $t$ має вигляд:

$$
\int_{0}^{t} k_{i} e^{-\alpha \tau} d \tau=\frac{k_{i}}{\alpha}\left(1-e^{-\alpha \tau}\right)
$$

Позначимо $i_{n}$ стан системи після $n$-го переходу, $u_{n}$ - прийняте рішення, а $\tau_{n}-$ час перебування в цьому стані $(n=0,1,2, \ldots), i_{0}-$ початковий стан. Допустиму стратегію $\beta$ для системи управління розробкою ПЗ визначимо як послідовність $\left\{\beta_{0}, \beta_{1}, \beta_{2}, \ldots\right\}$, де $\beta_{n}\left(\bullet / z_{n}\right)$ - імовірнісна міра, зосереджена на функції обмеження $U(S)$ на прийняті рішення (управління), що визначаються системою нерівностей:

$$
\sum_{j \in S} c_{r j} x_{r j} \leq b_{r}, \quad r \in R=\underset{j \in S}{U R_{j}},
$$

i яка залежить від історії керованої системи до моменту $n$-го переходу $z_{n}=\left(i_{0}, u_{0}, \tau_{0}, \ldots, i_{n-1}, u_{n-1}, \tau_{n-1}, i_{n}\right)$. Мiра $\beta_{n}\left(\bullet / z_{n}\right)$ задає рандомізоване правило вибору рішення $u_{n}$ на основі інформації $z_{n}$. Таку стратегію $\beta$ можна назвати рандомізованою.

Стратегія $\beta$ є марківською, якщо $\beta_{n}\left(\bullet / z_{n}\right)=\beta_{n}\left(\bullet / i_{n}\right)$, де $n=0,1,2, \ldots$. Марківська стратегія називається стаціонарною, якщо $\beta_{n}\left(\bullet / i_{n}\right)=\beta_{n}\left(\bullet / i_{n}\right)$. Щільність міри такої стратегії при $i_{n}=i, u_{n}=r,\left(r \in R_{i}\right)$ позначимо $d_{i}^{(r)}$. Якщо стратегія $\beta$ - марківська стаціонарна, то керований процес $\epsilon$ напівмарківським. 
Аналіз літератури показав, що найбільш популярна інформація про напівмарківські процеси і керовані напівмарківські моделі з додатковими витратами і дивідендами викладена в роботах [7-9].

Позначимо через $g_{i}(t, \alpha, \beta)$ сумарну витрату системи, керованої відповідно до стратегії $\beta, 3$ нормою переоцінки $\alpha$, за час $t$ життєвого циклу розробки ПЗ. Обов'язковою умовою $\epsilon$ те, що процес починається в момент $t=0$ зі стану $i$. Через $v_{i}(t, \alpha, \beta)=g_{i}(t, \alpha, \beta) / t$ позначимо сумарну середню витрату системи за час $t$ за тих самих умов.

Нехай $c_{r j}$ - витрати, пов'язані з реалізацією заходу $r$ у випадку події порушення безпеки ПЗ $r$ і $x_{r j}$ - булева змінна: $x_{r j}=1$, якщо $r$ застосовується при події $j, x_{r j}=0$ у протилежному випадку.

Припустимо, що загальний обсяг коштів, відпущених для усунення недоліків безпеки ПЗ (заходи типу $r$ ) обмежений константою $b_{r}$, тобто виконується нерівність (3).

Якщо витрати $c_{r j}$ дозволяють виконати кожне з обмежень (3), то реалізована на основі (3) система визначає у просторі $\mathfrak{R}^{d}, d=\operatorname{dim} R$, деяку кінцеву множину дискретних точок. Тоді, відповідно до робіт [7-9], існує нерандомізована стаціонарна стратегія $\beta^{*}$, що називається $\beta$ - оптимальною, яка мінімізує сумарну середню витрату $v(\alpha, \beta)$ при довільній стратегії $\beta$ і нормі переоцінки $\alpha(\alpha>0)$. При цьому $\alpha(\alpha>0) \epsilon$ $(N+1) \times 1$-мірний вектор $\left(v_{0}(\alpha, \beta), v_{1}(\alpha, \beta), \ldots, v_{N}(\alpha, \beta)\right)$, де

$$
v_{i}(\alpha, \beta)=\lim _{t \rightarrow \infty} v_{i}(t, \alpha, \beta), i \in S .
$$

Необхідно знайти $\alpha$-оптимальну нерандомізовану марківську стаціонарну стратегію $\beta^{*}$, яка мінімізує сумарну середню витрату $v(\alpha, \beta)$ при довільному початковому розподілі процесу

$$
\begin{gathered}
y=\left(y_{0}, y_{1}, \ldots, y_{N}\right), \\
\sum_{i \in S} y=1, y \geq 0, i \in S .
\end{gathered}
$$

Не зменшуючи спільності, як початковий розподіл візьмемо вектор $y=(1,0, \ldots, 0)$, тобто початковий стан системи. На основі напівмарківської моделі прийняття рішень дану задачу приведемо до еквівалентної задачі бівалентного програмування з використанням псевдобулевих методів.

Постановка завдання. Метою роботи є розробка методу управління ризиками розробки ПЗ, за умови обмеженості коштів виділених на усунення помилок безпеки.

Виклад основного матеріалу. Імовірності переходів розглядуваного, для системи розробки ПЗ, напівмарківського процесу прийняття рішень в моменти стрибків із стану $i$ в стан $j$ при прийнятті рішення $r \in R_{i}$ визначається стохастичною $(N+1) \times(N+1)$ матрицею $P^{(r)}=\left\{p_{i j}^{(r)}\right\}$, яка задає так званий вкладений ланцюг Маркова. Елементи $p_{i j}^{(r)}$ при будь-яких $i, j \in S$ і $r \in R_{i}$ дозволяють визначати за формулою (1) спільну ймовірність $Q_{i j}^{(r)}(t)$ того, що тривалість перебування у стані $i$ не перевищує час $t$ із стану $i$ при $r \in R_{i}$ процес переходить у стан $j$ з імовірністю $p_{i j}^{(r)}$. Функції $Q_{i j}^{(r)}(t)$ у (1) задовольняють умови:

$$
Q_{i j}^{(r)}(0)=0, i, j \in S, r \in R_{i}
$$




$$
\sum_{j \in S} Q_{i j}^{(r)}(\infty)=\sum_{j \in S} p_{i j}^{(r)}=1, i, \in S, r \in R_{i}
$$

За допомогою матриці $Q_{i j}^{(r)}(t)=\left\{Q_{i j}^{(r)}(t)\right\}$ перехідних розподілів визначимо функцію:

$$
H_{i}^{(r)}(t)=\sum_{j \in S} Q_{i j}^{(r)}(t), \quad i, \in S, r \in R_{i},
$$

що є функцією розподілу часу перебування процесу в стані $i$ при прийнятті рішення $r \in R_{i}$.

Випадковий процес $\left(Z_{t}\right), t \geq 0$ зі значеннями $Z_{t}=i$, якщо в момент $t$ система знаходиться в стані $i, \epsilon$ напівмарківським і задається величинами $N, y, Q_{i j}^{(r)}(t), i, j \in S, r \in R_{i}$.

Напівмарківський процес називається регулярним, якщо за кінцевий проміжок часу він з імовірністю $p_{p}=1$ перейде у будь-який стан не більше кінцевого числа разів. Таким чином, регулярний напівмарківський процес за кінцевий проміжок часу завжди здійснює лише кінцеве число переходів. Далі у роботі будемо розглядати тільки регулярні напівмарківські процеси.

У випадку одноелементних множин рішень $R_{i}$, у результаті стандартних для теорії відновлення [7-9] міркувань отримуємо наступне рівняння відновлення

$$
v_{i}(t)=\left(1-H_{i}(t)\right) \frac{k_{i}}{\alpha}\left(1-e^{-\alpha t}\right)+\sum_{j \in S} \int_{0}^{t}\left(\frac{k_{i}}{\alpha}\left(1-e^{-\alpha t}\right)+e^{-\alpha t} v_{j}(t-\tau)\right) d Q_{i j}(\tau), i \in S,
$$

де $v_{i}(t)$ - короткий запис сумарної середньої витрати $v_{i}(t, \alpha, \beta)$ за час $t$.

У випадку кінцевих множин $R_{i}$ рівняння відновлення 3 урахуванням імовірностей $d_{i}^{(r)}$ прийняття рішень $r$ у стані $i$ запишемо у вигляді:

$$
\begin{aligned}
& \mathrm{v}_{i}(t)=\sum_{r \in R_{i}} d_{i}^{r}\left(1-H_{i}^{(r)}(t)\right) \frac{k_{i}^{(r)}}{\alpha}\left(1-e^{-\alpha t}\right)+ \\
& +\sum_{j \in S} \sum_{r \in R_{i} 0} \int_{i} d_{i}^{r}\left(\frac{k_{i}^{(r)}}{\alpha}\left(1-e^{-\alpha t}\right)+e^{-\alpha t} \mathrm{v}_{j}(t-\tau)\right) d Q_{i j}^{(r)}(\tau), i \in S,
\end{aligned}
$$

де $k_{i}^{(r)}$ - витрата системи за одиницю часу перебування у стані $i$ при рішенні $r \in R_{i} ; v_{j}(t)$ - сумарна середня витрата $з$ урахуванням переоцінки (2) за умови, що процес починається в момент $t=0$ із стану $j$.

Величини $v_{i}(\alpha, \beta)$ із виразу 4 можна записати у вигляді $v_{i}(\alpha)$, i для цього рівняння скористатися основними положеннями рівняння (інтеграла) ЛапласаСтілтьєса. Відповідно до робіт [7-9] для будь-якої функції $F(t)$, похідна $F^{\prime}(t)$ якої є функцією-оригіналом, що задовольняє нерівність $F^{\prime}(t)<C e^{\alpha t}$ для всіх $t<0$, при всіх комплексних $s$, коли $\operatorname{Re} s>\alpha$ існує функція

$$
F^{*}(s)=L_{s}^{*}\langle F(t)\rangle=\int_{0}^{\infty} e^{-s t} d F(t),
$$

тобто функція $e^{-s t}$ при $\operatorname{Re} s>\alpha \in$ інтегрованою по функції $F(t)$. Функцію $F^{*}(s)$ називають перетворенням Лапласа-Стілтьєса функції $F(t)$. 
Із виразів 8 і 9 випливає, що $H_{i}^{(r)}(\infty)=1, \quad i \in S, r \in R_{i}$, тому перша сума у виразі 10 при $t \rightarrow \infty$ обертається на нуль. Інтегруючи по частинах вираз 11 для $L_{s}^{*}\langle F(t)\rangle$, отримуємо

$$
s L_{s}^{*}\langle F(t)\rangle=L_{s}^{*}\langle F(t)\rangle-F(0)
$$

де $F(s)=L_{s}\langle F(t)\rangle=\int_{0}^{\infty} e^{-s t} F(t) d t \epsilon$ перетворенням Лапласа функції $F(t)$.

Із 12 при $s \neq 0$ знаходимо

$$
L_{s}\langle F(t)\rangle=\frac{1}{s}\left(L_{s}^{*}\langle F(t)\rangle-F(0)\right) .
$$

Інтегруємо по частинах з урахуванням виразу 9 знаходимо

$$
\sum_{j} \int_{0}^{t}\left(1-e^{-\alpha t}\right) d Q_{i j}^{(r)}(\tau)=\left.\left(1-e^{-\alpha t}\right) \sum_{j} d Q_{i j}^{(r)}(\tau)\right|_{0} ^{t}-\sum_{j} \alpha \int_{0}^{t} e^{-\alpha t} H_{i}(\tau) d \tau
$$

Проводячи перетворення, переходячи у виразі 14 до границі $t \rightarrow \infty$ i застосовуючи формулу 13 для $s=\alpha,(\alpha>0), 3$ урахуванням співвідношень 7 і 8 , отримаємо

$$
\sum_{j} \int_{0}^{t}\left(1-e^{-\alpha t}\right) d Q_{i j}^{(r)}(\tau)=(1-\alpha) L_{s=\alpha}\left\langle H_{i}^{(r)}(\tau)\right\rangle=1-\alpha \frac{1}{\alpha} L_{s=\alpha}^{*}\left\langle H_{i}^{(r)}(\tau)\right\rangle=1-h_{i}^{(r)}(\alpha),
$$

де $h_{i}^{(r)}(\alpha)=L_{s=\alpha}^{*}\left\langle H_{i}^{(r)}(t)\right\rangle$.

Застосовуючи до функції $\Phi_{i}^{(r)}(t)=\int_{0}^{r} e^{-\alpha t} v_{j}(t-\tau) d Q_{i j}^{(r)}(t)$ теорему про граничний перехід в інтегралі по параметру, від якого залежать границі інтегрування i підінтегральна функція [7-9], при $t \rightarrow \infty$ отримуємо

$$
\Phi_{i}^{(r)}(\infty)=\int_{0}^{\infty} e^{-\alpha t} v_{j}(\alpha) d Q_{i j}^{(r)}(\tau)=v_{j}(\alpha) q_{i j}^{(r)}(\alpha)
$$

де $q_{i j}^{(r)}(\alpha)=L_{s=\alpha}^{*}\left\langle Q_{i}^{(r)}(\alpha)\right\rangle$.

Переходячи у виразі 10 до границі при $t \rightarrow \infty$, з урахуванням 15 і 16, отримуємо наступний аналітичний вираз:

$$
\begin{gathered}
\mathrm{v}_{i}(t)=\sum_{r \in R_{i}} d_{i}^{(r)}\left(\zeta_{i}^{(r)}(\alpha)\right)+\sum_{j \in S} q_{i j}^{(r)}(\alpha) v_{j}(\alpha), \\
\zeta_{i}^{(r)}(\alpha)=\frac{k_{i}^{(r)}}{\alpha}\left(1-h_{i}^{(r)}(\alpha)\right) .
\end{gathered}
$$

Нехай $\zeta_{i}(\alpha)=\sum_{r \in R_{i}} d_{i}^{r}\left(\rho_{i}^{(r)}(\alpha)\right)$ і $\Im(\alpha)=\left(\zeta_{0}(\alpha), \ldots, \zeta_{N}(\alpha)\right)^{T}, \wp(\alpha)=\left(v_{0}(\alpha), \ldots, v_{N}(\alpha)\right)^{T}$, (Т - символ транспонування матриці). Тоді

$$
\wp(\alpha)=\mathfrak{I}_{0}(\alpha)+q(\alpha) \wp(\alpha)
$$

де $q(\alpha)=\left\{q_{i j}(\alpha)\right\}, \quad q_{i j}(\alpha)=\sum_{r \in R_{i}} d_{i}^{(r)}\left(q_{i j}^{(r)}(\alpha)\right)$.

Із виразу (19) знайдемо

$$
\wp(\alpha)=\{I-q(\alpha)\}^{-1} \mathfrak{J}_{0}(\alpha) .
$$

Даний вираз справедливий, оскільки при $\alpha>0$ матриця $\{I-q(\alpha)\}$ - не вироджена, $I$ одинична матриця розміру $(N \times 1) \times(N \times 1)$. 
Помноживши обидві частини рівності 19 зліва на вектор $y$, отримаємо наступне

$$
\begin{gathered}
y v(\alpha)=\sum_{i \in S} \sum_{j \in \tilde{S}} \sum_{r \in R_{i}} y_{i} \mu_{i j}(\alpha) \zeta_{j}^{(r)}(\alpha) d_{i}^{(r)}, \\
\{I-q(\alpha)\}^{-1}=\left\{\mu_{i j}(\alpha)\right\} .
\end{gathered}
$$

Величини $\mu_{i j}(\alpha)$ залежать від $d_{i}^{(r)}, r \in R_{i}, i \in S$, оскільки елементи матриці $\{I-q(\alpha)\}$ можна виразити через $d_{i}^{(r)}, r \in R_{i}, i \in S$.

Нехай $\left\{d_{i}^{(r)}\right\}\left(r \in R_{i}\right)$ - нерандомізована марківська стаціонарна стратегія системи розробки ПЗ у стані $j-d_{j}^{(r)} \in\{0,1\}, \sum_{j \in S} d_{j}^{(r)}=1, \mathrm{i} x_{00}=1, x_{r j}=d_{j}^{(r)}, \quad r \in R_{i}, j \in \widetilde{S}$. Мінімізація витрат (21) приводить до наступної задачі оптимізації для булевих змінних $\mathrm{X}=\left\{x_{r j}\right\}, r \in R_{i}, j \in \widetilde{S}:$

$$
\begin{gathered}
f(\alpha, \mathrm{X})=\sum_{i \in S} \sum_{j \in \widetilde{S}} \sum_{r \in R_{i}} y_{i} \mu_{i j}(\alpha, \mathrm{X}) \zeta_{j}^{(r)} x_{r j} \rightarrow \min , \\
\sum_{r \in R_{i}} x_{r j}=1, j \in \widetilde{S}, \\
\sum_{j \in \widetilde{S}} c_{r j} x_{r j} \leq b_{r}, r \in R_{i}, j \in \widetilde{S}, \\
x_{r j} \in\{0,1\}, j \in \widetilde{S}, r \in R_{i} .
\end{gathered}
$$

Позначимо систему 24, 25 як систему $C$. Вона $\epsilon$ системою псевдобулевих нерівностей.

Підключивши далі додаткову умову 23 , можна позначити систему як $\widetilde{C}$. А через $\mathrm{X}_{r}^{(k)}=\left\{x_{r 1}^{(k)}, \ldots, x_{r N}^{(k)}\right\}, k=1, \ldots k_{r}-$ допустимі рішення $r$-ї нерівності системи $C$.

Для побудови рішень системи $\widetilde{C}$ при відомих допустимих рішеннях кожної нерівності 24 застосуємо наступний підхід. Рішення системи $\widetilde{C}$ знаходяться у вигляді $\mathrm{Z}=\left\{s_{j}\right\}, j=1, \ldots N$, де $s_{j}-$ множина номерів $r$, для яких допустима рівність $x_{r j}=1$. Рішення знаходяться за $m$ кроків, де $m$ - число обмежень 24 . У початковому стані кожна із множин $s_{j}^{(0)}$ вектора $Z^{(o)}$ включає усі можливі значення $r \in R_{i}$. На $r$-му кроці відбувається перетин вектора $Z^{(r-1)}$ з одним із рішень $r$-ї нерівності. Допускаючи, що $r$-ій нерівності відповідає $r=r_{1}$, а також, що $\alpha_{j} \in j$-м елементом допустимого рішення даної нерівності, $\alpha_{j} \in\{0,1, \varphi\}$, де $\varphi$ - невизначений параметр із множини $\{0,1\}$, званий в подальшому почерком, можна сформулювати наступні правила для $r$-го кроку алгоритму побудови рішень системи $\widetilde{C}$.

1. Якщо значення $\alpha_{j}$ не фіксоване, то $s_{j}^{(r)}=s_{j}^{(r-1)}$.

2. Якщо $\alpha_{j}=1$, то при $r_{1} \in s^{(r-1)}$ допускаємо $s^{(r)}=\left\{r_{1}\right\}$, а при $r_{1} \in s^{(r-1)}$ допускаємо $s^{(r)}$ рівне порожній множині.

3. Якщо $\alpha_{j}=0$, то допускаємо $s^{(r)}=s^{(r-1)} /\left\{r_{1}\right\}$.

При цьому перетин сімейств рішень здійснюється з урахуванням додаткових обмежень 23.

На $m$-му кроці алгоритму отримується вектор $Z^{(m)}=\left\{\alpha_{1}^{(m)}, \ldots, \alpha_{N}^{(m)}\right\}$, кожна компонента $\alpha_{j}^{(m)}$ якого є одноелементною множиною $\{r\}, \quad r \in R, \quad R=\{1, \ldots, m\}$ і отже, 
$\mathrm{Z}^{(m)} \epsilon$ рішенням системи $\widetilde{C}$. Виняток становлять випадки, коли $\widetilde{C}$ являє собою деякий набір чисел $r$ із множини $R$. В цьому випадку за допомогою поєднання елементів багатозначних компонент із вектора $Z^{(m)}$ можна отримати декілька рішень системи $\widetilde{C}$. Потім у результаті знаходимо сукупність усіх рішень системи $\widetilde{C}$, із яких вибираємо оптимальне рішення, що доставляє мінімум цільової функції $f(\alpha, \mathrm{X})$. Це рішення може знаходитися різними відомими методами лінійного програмування або просто шляхом безпосереднього порівняння значень $f(\alpha, \mathrm{X})$ при визначенні Х системи $\widetilde{C}$.

Чисельна реалізація викладеного методу управління ризиками безпеки індустрії програмного забезпечення для напівмарківської моделі прийняття рішень при аномальних ситуаціях безпеки представлена у наступному прикладі.

Розглянемо дві можливі ситуації помилок безпеки ПЗ: ситуація 1 - наявність функціональних помилок ПЗ (функціональні можливості ПЗ, не описані або ті, що не відповідають описаним у документації, при використанні яких можливе порушення конфіденціальності, доступності або цілісності оброблюваної інформації); ситуація 2 наявність нефункціональних помилок ПЗ (надлишкові ФО та IO, переповнення буфера, витоки пам’яті, помилки типів даних, помилки покажчиків та ін.).

Альтернативні заходи (спрощено) у випадку першої аномальної ситуації наступні:

- відкликання ПЗ (для усунення помилок);

- декомпозиція програми і оцінка метрик складності;

- сигнатурний аналіз.

У випадку наявності нефункціональних помилок ПЗ альтернативні заходи наступні:

- відкликання ПЗ (для усунення помилок);

- аналіз покажчиків, залежностей за даними та інтервальний аналіз.

Припустимо, що в обох ситуаціях перший захід (відкликання ПЗ) здійснюється за один і той же час $T=1$ y.e.. Тому, враховуючи низьку ціну відповідних функцій тестування в порівнянні зі збитками при простої ПЗ, можна вважати перші заходи в обох випадках однаковими за витратами.

Представимо заходи у випадку першої аномальної ситуації у вигляді $R=\left\{r_{1} ; r_{2} ; r_{3}\right\}$, а заходи для усунення другої аномальної ситуації у вигляді $R=\left\{r_{1} ; r_{4}\right\}$. Тоді число елементів системи складе $N=2$, а загальне число різних заходів для їх усунення $m=4$.

Також представимо описані аномальні ситуації $j$ по відношенню до окремих модулів і блоків ПЗ як послідовні з'єднання (за надійністю). Помилки (відмови) та їх усунення не впливають на надійність інших модулів та елементів ПЗ. Час усунення помилки не залежить від того, чи виявляються інші помилки у модулях, що залишилися. Іншими словами, кожна помилка виявляється і усувається незалежно від іншої. В цьому випадку потік помилок і заходів, що їх усувають, $\epsilon$ сумою $N$ незалежних процесів усунення з кінцевим часом відновлення.

Позначимо через $F_{j}(t)$ функцію розподілу часу експлуатації системи між двома послідовними аномальними ситуаціями типу $j$, а через $G_{j}^{(k)}(t)$ - функцію розподілу часу усунення помилки після аномальної ситуації типу $j$ при прийнятті рішення $r$. Будемо вважати, що $F_{j}(t)$ і $G_{j}^{(k)}(t)$ підпорядковуються експоненціальним законам 3 функціями інтенсивності відповідно $\lambda_{j}$ і $\mu_{j}^{(k)}$ : 


$$
F_{j}(t)=1-e^{-\lambda_{j} t}, G_{j}^{(k)}(t)=1-e^{-\mu_{j}^{(r)} t},
$$

де $\lambda_{j}=1 / T_{j_{1}} ; \mu_{j}^{(r)}=1 / T_{j 2} ; T_{j_{1}}-$ середній час експлуатаційного етапу життєвого циклу розробки ПЗ між двома аномальними ситуаціями типу $j ; T_{j 2}-$ середній час відновлювального етапу життєвого циклу розробки ПЗ після виявлення помилки типу $j$ при рішенні $r$.

Нехай $d_{i}^{(k)}$ - нерандомізована стаціонарна стратегія системи у стані $i(i \in S)$ при рішенні $k$ (тобто ймовірність прийняття рішення $r$ у стані $i$ ),

$$
d_{i}^{(r)} \in\{0,1\}, \sum_{k \in K} d_{i}^{(r)} \in 1, i \in S .
$$

Тоді закон розподілу експлуатації і закон розподілу усунення помилок в цілому запишемо у вигляді

$$
F_{j}(t)=1-e^{-\lambda t}, G_{j}^{(r)}(t)=1-e^{-\mu t},
$$

де $\lambda=\sum_{j=1}^{N} \lambda_{j} ; \mu=\sum_{j=1}^{N} \sum d_{j}^{(r)} \mu_{j}^{(r)}$.

Нехай

$$
\begin{aligned}
& T_{11}=8 \text { y.e, } \quad T_{21}=8 \text { y.e, } \quad T_{12}^{(1)}=1 \text { y.e, } \quad T_{12}^{(2)}=2 y \cdot e, \quad T_{12}^{(3)}=1 \text { y.e }, \\
& T_{22}^{(1)}=1 \text { y.e, } \quad T_{22}^{(4)}=0,5 y \cdot e
\end{aligned}
$$

Припустимо, що $i=0$ фіксує нормальний стан, $i=1$ аномальний стан (ситуація 1), $i=2$ аномальний стан (ситуація 2); $S=\{0,1,2\}, \quad \widetilde{S}=\{1,2\}$. Відповідно до умови 28 і враховуючи вирази 25-27, отримаємо:

$$
\begin{aligned}
& F_{0}(t)=F(t)=1-e^{-0,25 t}, F_{j}(t)=1-e^{-0,125 t}, j=1,2 ; \\
& G_{1}^{(1)}(t)=1-e^{-t}, G_{1}^{(2)}(t)=1-e^{-0,5 t}, G_{1}^{(3)}(t)=1-e^{-t}, \\
& G_{2}^{(1)}(t)=1-e^{-t}, G_{2}^{(4)}(t)=1-e^{-2 t} .
\end{aligned}
$$

Нехай витрати від невиконання своїх функцій програмною системою протягом часу $T=1 \iota$ складуть 70000 у.о.. Позначимо через $c_{k, j}$ витрати на захід $k$ у випадку аномальної ситуації $j$. Тоді, нехтуючи витратами на тестування в заході $r=1$, отримуємо $c_{1,1}=c_{1,2}=c_{1}=70000$ у.о.. Нехай далі $c_{2,1}=300, c_{3,1}=400, c_{4,2}=600$ у.о.. Будемо вважати, що у стані $i=0$ прийнято єдине рішення $(r=0)$ - продовжити нормальне функціонування, і в цьому стані задано наступний розподіл імовірностей:

$$
p_{00}^{(0)}=0,7, p_{01}^{(0)}=0,1, p_{02}^{(0)}=0,2 .
$$

Функції (1) i (9) запишемо як

$$
\begin{gathered}
Q_{00}^{(0)}(t)=0,7\left(1-e^{-0,25 t}\right), Q_{01}^{(0)}(t)=0,1\left(1-e^{-0,125 t}\right), \\
Q_{02}^{(0)}(t)=0,2\left(1-e^{-0,125 t}\right), Q_{10}^{(1)}(t)=\left(1-e^{-t}\right), Q_{10}^{(2)}(t)=\left(1-e^{-0,5 t}\right), \\
Q_{10}^{(3)}(t)=\left(1-e^{-t}\right), Q_{11}^{(k)}(t)=Q_{12}^{(k)}(t)=0, \quad(k=1,2,3), \\
Q_{20}^{(1)}(t)=\left(1-e^{-t}\right), Q_{20}^{(4)}(t)=\left(1-e^{-2 t}\right), \\
H_{0}^{(0)}(t)=0,7\left(1-e^{-0,25 t}\right)+0,3\left(1-e^{-0,125 t}\right), \\
H_{1}^{(0)}(t)=\left(1-e^{-0,25 t}\right), H_{1}^{(2)}(t)=\left(1-e^{-0,5 t}\right), H_{1}^{(3)}(t)=\left(1-e^{-t}\right),
\end{gathered}
$$




$$
H_{2}^{(1)}(t)=\left(1-e^{-t}\right), H_{2}^{(4)}(t)=\left(1-e^{-2 t}\right)
$$

3 урахуванням позначень $\quad x_{00}=1, x_{k, j}=d_{j}^{(k)}, r \in R_{j}, j \in \widetilde{S} \quad$ матриця $q(\alpha, x)=\left\lfloor q_{i, j}(\alpha, x)\right\rfloor(i, j \in S)$ з елементами

$$
q(\alpha, x)=\sum_{r \in R_{j}} x_{k, i} q_{i, j}^{(r)}(\alpha)(i, j \in S)
$$

набуде вигляду

$$
q(\alpha, x)=\left[\begin{array}{ccc}
\frac{0,175}{\alpha+0,25} & \frac{0,0125}{\alpha+0,125} & \frac{0,025}{\alpha+0,125} \\
\frac{x_{11}+x_{31}}{\alpha+1}+\frac{x_{21}}{\alpha+0,5} & 0 & 0 \\
\frac{x_{12}}{\alpha+1}+\frac{x_{42}}{\alpha+2} & 0 & 0
\end{array}\right]
$$

Знайдемо визначник матриці $[I-q(\alpha, x)]$ :

$$
D(\alpha, x)=-\frac{0,025}{\alpha+0,125}\left(\frac{x_{12}}{\alpha+1}+\frac{2 x_{42}}{\alpha+2}\right)+1-\frac{0,175}{\alpha+0,25}-\frac{0,0125}{\alpha+0,125}\left(\frac{x_{11}}{\alpha+1}+\frac{x_{21}}{\alpha+0,5}\right) .
$$

Матриця $[I-q(\alpha, x)]^{-1}=\left[\mu_{i, j}(\alpha, x)\right],(i, j \in S)$ має елементи

$$
\begin{aligned}
& \mu_{00}(\alpha, x)=0, \mu_{01}(\alpha, x)=\frac{1}{D(\alpha, x)} \frac{0,0125}{\alpha+0,125}, \mu_{02}(\alpha, x)=\frac{1}{D(\alpha, x)} \frac{0,025}{\alpha+0,125}, \\
& \mu_{10}(\alpha, x)=\frac{1}{D(\alpha, x)}\left(\frac{x_{11}+x_{31}}{\alpha+1}+\frac{x_{21}}{\alpha+0,5}\right), \\
& \mu_{11}(\alpha, x)=\frac{1}{D(\alpha, x)}\left(1-\frac{0,175}{\alpha+0,25}-\frac{0,0125}{\alpha+0,125}\left(\frac{x_{12}}{\alpha+1}+\frac{2 x_{42}}{\alpha+2}\right)\right), \\
& \mu_{12}(\alpha, x)=\frac{1}{D(\alpha, x)} \frac{0,025}{\alpha+0,125}\left(\frac{x_{11}+x_{31}}{\alpha+1}+\frac{x_{21}}{\alpha+0,5}\right), \\
& \mu_{20}(\alpha, x)=\frac{1}{D(\alpha, x)}\left(\frac{x_{12}}{\alpha+1}+\frac{2 x_{42}}{\alpha+2}\right), \\
& \mu_{21}(\alpha, x)=\frac{1}{D(\alpha, x)} \frac{0,0125}{\alpha+0,125}\left(\frac{x_{12}}{\alpha+1}+\frac{2 x_{42}}{\alpha+2}\right), \\
& \mu_{22}(\alpha, x)=\frac{1}{D(\alpha, x)}\left(1-\frac{0,0175}{\alpha+0,25}-\frac{0,0125}{\alpha+0,125}\left(\frac{x_{11}+x_{31}}{\alpha+1}+\frac{x_{21}}{\alpha+0,5}\right)\right) .
\end{aligned}
$$

У виразі $18 k_{i}^{(r)}$ набувають наступних значень:

$$
k_{0}^{(0)}=70000 \text { y.e }, \quad k_{1}^{(1)}=-70000 y . e, \quad k_{1}^{(2)}=-150 y . e, \quad k_{1}^{(3)}=-400 \text { y.e },
$$
$k_{2}^{(1)}=-70000$ y.e, $k_{2}^{(4)}=-12000$ y.e.,

а величини $\zeta_{i}^{(r)}$ записуються у вигляді: 


$$
\begin{gathered}
\zeta_{0}^{(0)}(\alpha)=\frac{70000}{\alpha}\left(1-\frac{0,175}{\alpha+0,25}-\frac{0,0375}{\alpha+0,125}\right), \zeta_{1}^{(1)}(\alpha)=-\frac{70000}{\alpha}\left(1-\frac{1}{\alpha+1}\right), \\
\zeta_{1}^{(2)}(\alpha)=-\frac{150}{\alpha}\left(1-\frac{0,5}{\alpha+0,5}\right), \zeta_{1}^{(3)}(\alpha)=-\frac{400}{\alpha}\left(1-\frac{1}{\alpha+1}\right), \zeta_{2}^{(1)}(\alpha)=-\frac{70000}{\alpha}\left(1-\frac{1}{\alpha+1}\right), \\
\zeta_{2}^{(4)}(\alpha)=-\frac{1200}{\alpha}\left(1-\frac{2}{\alpha+2}\right) .
\end{gathered}
$$

Знайдемо рішення системи $\widetilde{C}$ за допомогою алгоритму перетину рішень окремих нерівностей (24), вважаючи, що праві частини $b_{k}$ цих нерівностей задовольняють умови:

$$
c_{11}<b_{1}<2 c_{1}, b_{2}>c_{21}, b_{3}>c_{31}, b_{4}>c_{42} \text {. }
$$

3 урахуванням умов (30) знаходимо наступні рішення окремих нерівностей системи $\widetilde{C}$ :

$$
\begin{aligned}
& r_{1}=1: 1-(1,0) ; 2-(0,1), 3-(0,0) ; \\
& r_{1}=2: 1-(1,0) ; 2-(0,0) ; \\
& r_{1}=3: 1-(1,0) ; 2-(0,0) ; \\
& r_{1}=4: 1-(0,1) ; 2-(0,0) .
\end{aligned}
$$

За наявності $Z^{(0)}=\{\{1,2,3\},\{1,4\}\}$ на останньому кроці алгоритму отримуємо:

$$
\begin{aligned}
& \mathrm{Z}_{1221}^{(4)}=\{\{1\},\{4\}\}, \\
& \mathrm{Z}_{1222}^{(4)}=\{\{1\}, \text { порожня множина }\}, \\
& \mathrm{Z}_{2121}^{(4)}=\{\{2\}, \text { порожня множина }\}, \\
& \mathrm{Z}_{2222}^{(4)}=\{\{\{2\},\{1\}\}, \\
& \mathrm{Z}_{2211}^{(4)}=\{\{3\}, \text { порожня множина }\}, \\
& \mathrm{Z}_{2212}^{(4)}=\{\{3\},\{1\}\}, \\
& \mathrm{Z}_{3121}^{(4)}=\{\{\{2\},\{4\}\}, \\
& \mathrm{Z}_{3122}^{(4)}=\{\{2\}, \text { порожня множина }\}, \\
& \mathrm{Z}_{3211}^{(4)}=\{\{3\},\{4\}\}, \\
& \mathrm{Z}_{3212}^{(4)}=\{\{3\}, \text { порожня множина }\} .
\end{aligned}
$$

Таким чином, рішеннями системи $\widetilde{C} є$ вектори:

$1-\{\{1\},\{4\}\}, 2-\{\{2\},\{1\}\}, 3-\{\{3\},\{1\}\}, 4-\{\{2\},\{4\}\}, 5-\{\{3\},\{4\}\}$.

Їм відповідають наступні значення булевих змінних $\left\{x_{k, j}\right\}$ :

1) $x_{1,1}=1, x_{4,2}=1$;

2) $x_{2,1}=1, x_{1,2}=1$;

3) $x_{2,1}=1, x_{4,2}=1$;

4) $x_{3,1}=1, x_{1,2}=1$;

5) $x_{3,1}=1, x_{4,2}=1$.

Не вказані змінні в кожному $i$-му рішенні дорівнюють нулю.

3 урахуванням виразів 28 і $29 f(\alpha, x)$ при $\alpha=0,1$, що відповідає інфляції, яка дорівнює $10 \%$, і початковому розподілу $y=(1,0, \ldots, 0)$ набуває значення: 


$$
f_{1}=-51903 ; f_{2}=-5329040 ; f_{3}=-17161 ; f_{4}=-26939 ; f_{5}=-3325 \text {. }
$$

Таким чином, при $\alpha=0,1$ i $y=(1,0, \ldots, 0)$ оптимальною нерандомізованою марківською стаціонарною стратегією буде стратегія $x_{1,1}=0, x_{2,1}=0, x_{3,1}=1, x_{1,2}=0$, $x_{4,2}=1$, що відповідає рішенню $\{\{3\},\{4\}\}$ системи $\widetilde{C}$.

\section{Висновки.}

У роботі вирішена задача управління ризиками розробки ПЗ за умови обмеженості коштів (фінансових, технічних та ін.), виділених на усунення помилок безпеки, та удосконалено метод управління ризиками розробки ПЗ. Для вирішення задачі був запропонований метод, в основу якого була покладена напівмарківська модель прийняття рішень для керованого марківського процесу в безперервному часі. Відмінною особливістю запропонованого методу $\epsilon$ використання псевдобулевих методів бівалентного програмування 3 нелінійною цільовою функцією і лінійними обмеженнями для визначення оптимальної стратегії усунення експлуатаційних помилок.

Проведені дослідження показали, що використовувані в даній роботі теоретичні положення у достатньому обсязі відображають стандарти і можливості сучасних методологій тестування ПЗ.

Як приклад розглянуті ситуації виникнення помилок безпеки ПЗ і визначена оптимальна стратегія управління для усунення вказаної аномальної ситуації.

Слід зауважити, що представлений у роботі метод доцільно використовувати не тільки при управлінні ризиками безпеки ПЗ, але і при функціональному, навантажному, стресовому та інших видах тестування для запобігання можливих витрат.

Подальші дослідження направлені на алгоритми тестування на вразливість до одних із найбільш розповсюджених видів атак на web-додаток - DOM XSS та SQL ін'єкції.

\section{Список літератури}

1. Krishnan M. Soumya Software Development Risk Aspects and Success Frequency on Spiral and Agile Model [Text] / M. Soumya Krishnan // International Journal of Innovative Research in Computer and Communication Engineering (An ISO 3297: 2007 Certified Organization) Vol. 3, Issue 1, January 2015. P.301-310.

2. Zeng Y. Risk Management For Enterprise Resource Planning System Implementations in Project-Based Firms : dis. for the degree of PHD [Text] / Zeng Yajun, Maryland, 2010 - P. 210.

3. Бриткин А.И. Риски, связанные с внедрением технологий, в проектах разработки программного обеспечения [Текст] / А. Бриткин // Социально-экономические и технические системы. $-2007 .-$ № $8(42)$.

4. Коваленко А.В. Задачи распознавания ситуаций в ERP системах [Текст] / А.В. Коваленко, А.А. Смирнов, А.С. Коваленко // Збірник наукових праць "Системи обробки інформації". - Вип. 4(120). - Х.: ХУПС, 2014. - С. 161-164.

5. Коваленко А.В. Методы качественного анализа и количественной оценки рисков разработки программного обеспечения [Текст] / А.А. Смирнов, А.В. Коваленко // Збірник наукових праць "Системи обробки інформації". - Вип. 5(142). - Х.: ХУПС, 2016. - С. 153-157.

6. Метод количественной оценки рисков разработки программного обеспечения [Текст] / А.А. Смирнов, А.В. Коваленко, Н.Н. Якименко, А.П. Доренский // Збірник наукових праць Харківського університету Повітряних Сил. -2016. - № 2. - С. 128-133.

7. Будников С.А. Полумарковская модель сложного конфликта радиоэлектронных систем [Текст] / Методы и средства управления технологическими процессами: материалы V Международной конференции (19 - 21 ноября 2009 года). - Саранск, 2009. - С. 201-223.

8. Литвиненко К.В. Полумарковский гиперслучайный подход к оценке рисков систем [Текст] / К.В. Литвиненко // Збірник наук. праць ОДАТРЯ. - 2014. - №1(4). - С.77-80

9. Гнеденко Б.В. Введение в теорию массового обслуживания . - изд. 3-е, испр. и доп. [Текст] / Б.В. Гнеденко, И.Н. Коваленко. - М.: КомКнига, 2005. - 400 с 


\section{References}

1. Krishnan, M. (2015). Soumya Software Development Risk Aspects and Success Frequency on Spiral and Agile Model. International Journal of Innovative Research in Computer and Communication Engineering (An ISO 3297: 2007 Certified Organization), 3 (1), 301-310.

2. Zeng, Y. (2010). Risk Management For Enterprise Resource Planning System Implementations in Project-Based Firms. Candidate's thesis. Maryland.

3. Britkin, A.I. (2007). Riski, svjazannye s vnedreniem tehnologij, v proektah razrabotki programmnogo obespechenija [Risks associated with the introduction of technology in software development projects]. Social'no-jekonomicheskie i tehnicheskie sistemy - Socio-economic and engineering systems, 8 (42), 156168.

4. Kovalenko, O.V., Smirnov, O.A. \& Kovalenko, A.S. (2014). Zadachi raspoznavanija situacij v ERP sistemah [Problem recognition situations in ERP systems]. Sistemi obrobki informacii - Information Processing Systems, 4(120), 161-164.

5. Kovalenko, O.V. \& Smirnov, A.A. (2016). Metody kachestvennogo analiza i kolichestvennoj ocenki riskov razrabotki programmnogo obespechenija [Methods of qualitative analysis and quantitative risk assessment software development]. Sistemi obrobki informacï-Information Processing Systems, 5(142), $153-157$

6. Kovalenko, O.V., Smirnov, O.A., Jakimenko, N.N. \& Dorenskij, O.P. (2016). Metod kolichestvennoj ocenki riskov razrabotki programmnogo obespechenija [Method of quantitative risk assessment software development]. Zbirnik naukovih prac' Harkivs'kogo universitetu Povitrjanih Sil - Scientific Works of Kharkiv National Air Force University, 2 (47), 128-133.

7. Budnikov, S.A. (2009). Polumarkovskaja model' slozhnogo konflikta radiojelektronnyh sistem [The semiMarkov model of a complex conflict of electronic systems]. Technological process control methods and tools '9: V Mezhdunarodna konferencia (19-21 nojabrja 2009 hoda.) - 5 International Conference (pp. 201-223). Saransk.

8. Litvinenko, K.V. (2014). Polumarkovskij gipersluchajnyj podhod k ocenke riskov sistem [The Semi Markov hyper casual approach to the estimation of risks of systems]. Zbirnik naukovih prac' ODATRJaCollection of scientific works of the OSATRQ, 1(4), 77-80.

9. Gnedenko, B.V. \& Kovalenko, I.N. (2005). Introduction to queuing theory. (3d ed.). Moscow: Komkniga.

Oleksandr Kovalenko, Assoc. Prof., PhD tech. sci.

Central Ukrainian National Technical University, Kropyvnytsky, Ukraine,

\section{Risk Management Software Development, Subject to the Limited Funds Allocated to the Elimination of Security Errors}

The conducted researches showed that risk management of software development consists in the early detection of financial, technical, psychological and other related risks. hazards, and taking measures to reduce the risk by deliberately changing these factors, taking into account the effectiveness of the measures taken. Risk management software development includes a system of measures that are carried out both to the occurrence of a negative event and after its implementation. However, as studies have shown, preventive analysis and taking into account the majority of possible operational errors will reduce financial and other issues. expenses in the life cycle of software development.

The purpose of the work is to develop a method for managing the risks of software development, provided that the funds allocated to eliminate security errors are limited.

In this paper, the problem of risk management of software development on the condition of limited funds (financial, technical, etc.), allocated for the elimination of security errors, is considered as a semi-Markov decision making model for a managed process in a continuous time with a criterion for minimizing the cost of eliminating anomalies. To solve the problem, we propose a method for managing the risks of software development, which differs from the known use of pseudo-Boolean methods of bivalent programming with a nonlinear target function and linear constraints to determine the optimal strategy for eliminating operational errors. As an example, situations of software security error occurrence are considered and an optimal management strategy is identified for eliminating this abnormal situation.

The conducted studies have shown that the theoretical positions used in this paper adequately reflect the standards and capabilities of modern software testing methods. It should be noted that the method presented in the work should be used not only in the management of software security risks, but also in functional, load, stress and other types of testing to prevent possible costs.

software development, risk management, pseudo-Boolean method

Одержано (Received) 31.05.2018 